\title{
CORRIGENDUM
}

\section{Epigenetic control of metastasis-associated protein 1 gene expression by hepatitis B virus $\mathrm{X}$ protein during hepatocarcinogenesis}

M-H Lee, H Na, T-Y Na, Y-K Shin, J-K Seong and M-O Lee

Oncogenesis (2014) 3, e88; doi:10.1038/oncsis.2014.4; published online 17 February 2014

Correction to: Oncogenesis (2012) 1, e25; doi:10.1038/oncsis.2012.26; published online 3 September 2012

The authors of this study have noticed an error in Figure $4 a$ of their paper. After the publication of the article, the authors found Figure 4a was duplicated from the panel of Figure $5 \mathrm{~d}$. The error was unintentionally introduced during figure pre- paration and is not a correct representation of the data. The authors have now provided correct representative data for Figure $4 \mathrm{a}$ as shown below. The error in the original published manuscript does not in any way alter the results or conclusion of this study. The authors apologize that these errors were not detected earlier. a

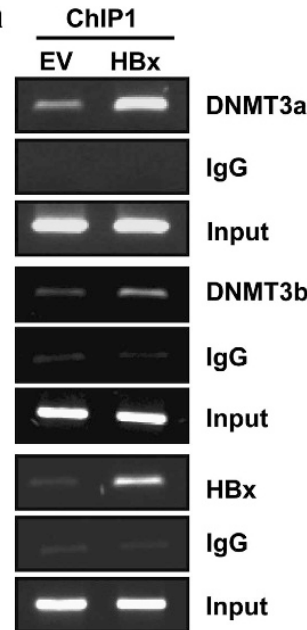

